\title{
Identity, Recognition or Redistribution through Sport?
}

\author{
Grant Jarvie
}

University of Stirling, UK

\section{ABSTRACT}

Identity has long since been a key concept within historical, sociological and philosophical enquires into sport. This article asserts that identity politics in sport is not enough and alternative forms of thinking about identity need to challenge the conventional wisdom that identity for identity sake is sufficient. By introducing the notions recognition and re-distribution this research attempts to move the field of sport on. Only by looking at alternative conceptions of the links between identity, redistribution and recognition can we meet the requirements of justice for all through and in sport. This article addresses the following concerns (i) sport in the age of identity politics; (ii) from identity politics to recognition through sport and (iii) from recognition through sport to redistribution and social justice.

\section{KEYWORDS}

identity, justice, recognition, re-distribution, sport

The concept of identity has had a long history in relation to sport. Formulaic constructions of identity in sport have become a symptomatic feature of much of the present body of knowledge that informs our thinking about sport in society. Yet perhaps it is time to move on from - or at least think differently about - a concept that has grown out of proportion, is vaguely misrepresented, and at times appears to be a signature phrase or rationale in itself for talking and writing about a wide range of topics such as sport and nationalism, sport and religion, and sport and ethnicity, to name but three areas where the word is loosely used. The term 'identity' itself, while tending to assert a common essence to which special meaning are attached, is in itself weaker than terms such as recognition. Is it not recognition in and through sport that so-called collective identities are seeking to establish, challenge and consolidate rather than just identity?

There are numerous shades of the same basic argument about sport, namely that sport can provide the technical means for creating political and/or social identities and that these are thereby reflected or embedded within national and local cultural identities. This is often reinforced by suggestions that political identities in sport can help challenge a certain world order and allegedly prepare the way for democratization. Examples that are illustrative of this line of thought - that sport has helped to pave the way for forms of democratization or liberalism - include cricket and the break from colonialism in the Caribbean during the 1960s; table tennis diplomacy in the China of the early 1970s; rugby and soccer in apartheid South Africa up until the early 1990s; and the significance of athletics and in particular middle-distance running in Kenya and Ethiopia. The term 'identity through sport' is often evoked to depict a strong national identity but in reality it often obscures a wide range 
of scientific, political and sometimes religious questions, and it is tempting to suggest that the concept of identity as it is used in writings about sport seems particularly well suited to function as an ostensive screen, camouflaging vagueness of content in a blaze of expression. If identity is a signifier that carries with it histories of sport or people or nation then it is important not to conflate or camouflage the complexity of sport through the use of stereotypes or plastic words such as identity. It certainly must not be confused with the struggle for recognition that is ongoing through sport.

Contemporary struggles for recognition in and through sport often take on the guise of particular forms of social identity. This is often aimed at championing the cause for a particular social difference or form of representation from disenfranchised or less powerful sections of sport. In the first instance, such approaches to sport and identity might be misconceived on at least three accounts: (i) the failure to foster authentic collective identities across differences has tended to enforce separatism, conformism and intolerance; (ii) the struggle for identity in and through sport has often tended to replace struggles for economic justice and the redistribution of wealth often condemning different sporting groups to some grave injustices; (iii) the failure to realise that while levels of social inequality between and within certain groups maybe decreasing, levels of poverty in certain places continue to increase. Is not the primary motivation for many Kenyan and Ethiopian runners not to run for the sake of identity but instead to gain recognition and in many cases capitalise upon the opportunity to escape poverty? The notion of identity through sport for the sake of identity is not enough on its own; therefore, alternative forms of social thinking about the sport and identity are urgently required.

\section{Sport in the age of identity politics}

The rise of identity politics and identity history in sport form a certain kind of logic of their own that has been attractive to writers who have sought to comment upon changes in sport, culture and society after about 1990. Yet few writers have offered an analysis of sport during what Balakrishnan (2002) critically refers to as the age of identity, or what Woodward (2002) refers to as the crisis of identity. The march towards global sport has meant that the processes associated with globalisation have placed questions of identity central stage in terms of explaining the importance of sport, for example, to those countries that have emerged out of the break-up of the former USSR or other former European countries such as former Yugoslavia. Many nationalist movements during the latter part of the twentieth century have fought to develop and sustain forms of identity. Sport has become one of the visible forums for expression of such imagined communities, whether they be nationalist in orientation or not.

The rise of identity politics in sport is a mode of logic, a badge of belonging and a claim to insurgency. It operates across states but also through the personal in the sense that calls for identity have come from a myriad of traditionally marginalised groups. Identity politics presents itself as a quest from anonymity in an individualised, impersonal world in that groups, countries, individuals are searching for answers to a cluster of questions such as Who am I? Who is like me? Whom can I trust? and Where do I belong? In practice, identity politics in sport slides toward an uncritical acceptance of the premise that social groups have essential identities which if enforced run the tendency to forge divisions, separation, and fragmentation. Yet in essence all identity politics involves a search for community, a quest for belonging and recognition. The problem with this - and the point I wish to assert - is that the thickening of identity politics through sport is inseparable from the fragmentation of sport as different groups assert their identity. In large measure the hypothetical challenge to sport is that while being the focus for a myriad of identities, personal politics as well as national identities, something at the centre needs to hold sport together. The idea of commonality or social sport or the quest for community runs the danger of being replaced by separate assertions of fundamental identities that can only lead to fragmentation.

Rarely do you find carefully crafted accounts of identity politics in sport that empirically substantiate different accounts of identity in sport while at the same time confirming what Naomi 
Klein (2001) has called reclaiming the commons. What this means is the formulation of a political framework that can take on corporate power and control and empower local organisation in sport while at the same time valuing human diversity and recognition in sport. There are concerns about all kinds of prosaic issues in sport in the twenty-first century, to the extent that sport at times is taken out of its own hands and into courts of law or company board rooms of the major global companies. There is little room here for local decisions or concerns about human diversity. The 2004 Olympic women's marathon in Athens was run at a time to suit American television, not the athletes and not the local organisers of the games. The goal for sport should not be better far-away rules, or forms of governance by faceless rulers, but close-up democracy on the ground.

One of the few carefully crafted studies of human diversity and identities in sport that respects the common ground is Jennifer Hargreaves' account (2000) of the politics of difference and identity amongst sporting heroines. The story of these sporting heroines does not loose sight of the common ground of social relations, different social divisions and women's sporting experiences across the globe. At the same time, the stories of sport that are told illuminate exclusion, difference and identity in sport as experienced by black women in South Africa, Muslim women in the Middle East, Aboriginal women in Australia and Canada, as well as lesbian and disabled women. All of these accounts of heroines in sport have contributed to knowing more about the lives of ordinary women, many of whom are on the margins of mainstream sport, and how their own personal and group identities tell you something about who they are and who they belong to and trust. This courageous account of sporting heroines is all the more politically powerful because it avoids the danger of presenting a fragmented list of identity politics in sport that are disconnected and fragmented from the common ground of social relations, power and human diversity in sport. It is very much a social account of sport that champions the cause of the public intellectual in sport making a difference, struggling for a new world order and recognising that identities in sport are not fixed but subject to continuous interpretation and re-interpretation. This account of the identities of sporting heroines avoids the temptation of so many feminist accounts of sport published in the 1970s and 1980s that tended to champion the alter ego of white middle-class women in sport.

The typical contemporary approach to identity politics in sport tends to start from the idea that identity is constructed dialogically (Fraser 2000). The proposition is that identity is forged by virtue of the fact that one becomes an individual subject only by virtue of recognizing and being recognized by another subject or group. Recognition is seen as being essential to developing a sense of self and being mis-recognized involves suffering a sense of distortion of one's relation to one's self and consequently feeling an injured sense of identity. This logic is transferred to the cultural and political terrain. As a result of repeated encounters with the stigmatising gaze and the resultant internalising of negative self or group images, the development of a healthy cultural identity is affected. Within this perspective, the politics of recognition through sport is mobilised as a potential strategy in the repair of self or group dislocation by affirmative action that challenges derogatory or demeaning pictures of the group. The argument is that members of mis-recognised groups or groups suffering from a lack of identity can jettison such images in favour of self-representations of their own making and collectively produce a self-affirming culture of recognition. Add to this public assertion and the gaining of respect and esteem from society at large and a culture of distorted mis-recognition changes to being one of positive recognition.

This model of how identity politics in sport may operate contains some genuine insights into the effects and practice of racism, sexism, colonization, nationalism, imperialism and other forms of identity politics that operate through sport. Yet the model is both theoretically and politically problematic in that such an approach leads to both the reification of group identity and the displacement of resource distribution. The problems of displacement and the reification of social and political identities in sport are serious problems insofar as the politics of recognition displaces the politics of redistribution and may actually promote inequality. In the 1970s and 1980s identity politics in sport was imbedded with emancipatory promise and potential, yet at the turn of the century the 
identity politics of sport had transformed itself into a reified school of thought that recognizes identity as an end in itself rather than recognition accompanied by resource redistribution. Those who promote identity politics in sport as opposed to the politics of recognition run the danger of encouraging separatism, intolerance, chauvinism, authoritarianism and forms of fundamentalism. This then is the problem of reification and identity politics in sport that shall be discussed further in this chapter. What is being argued here is the need to develop accounts of recognition in sport that can accommodate the full complexity of social identities instead of promoting reification and separatism. This means developing accounts of recognition in sport that allow for issues of redistribution rather than displacing or undermining such concerns in relation to sport, culture and society.

By means of summary it might be suggested that some or all of the following arguments have been utilised in an examination of identity politics in sport: (i) that essentialist arguments are those which view identity in sport as fixed and unchanging; (ii) that sporting identities are linked to claims about culture, self and/or nature; (iii) that sporting identity is relational and differences are established by symbolic marking in and around sport. Sport contributes to both the social and the symbolic processes involved with the forging of identities; (iv) that sport simply reflects changes that have accompanied the age of identity and, in this sense, identity in sport may refer to a phase or period in history; (v) that identity politics in sport are reproduced or maintained through changing social and material conditions; (vi) that identity in sport involves classifying people into different permutations of us and them; (vii) that identity in sport involves both the promotion and obscuring of certain differences; (viii) that identities in sport are not unified and contradictions within them involve negotiation; (ix) that, when reified, identity politics in sport may lead to forms of fundamentalism; (x) that the quest for identity through sport involves the quest for recognition.

\section{Bodies, identities and differences}

The study of the body is an additional area of work offering endless possibilities and points of entry and exit from historical, geographical and contemporary examinations of sporting identities and differences. Even the most cursory glance at critical academic literature on sport and related activities such as exercise, physical culture and health provides the reader with an array of bodies: the athletic body; the sporting body; the fascist body; the racialized body; the black body; the oriental body; the engendered body; the civilized body; the bodybuilder; the female body; the male body; gay and lesbian bodies; the body habitus and the African body. All of these have been invested in as a basis of telling us about different identities, differences and representations. The rise of identity politics and the place of the body and sport within what Balakrishnan (2002) refers to as the age of identity may have increased our understanding of embodiment in some societies but such an approach also contain certain risks.

Given that the identity model and sport is brought into question and explored further in chapter fourteen of this book, the discussion in this section is limited to commentary on three central ideas that any student or researcher needs to navigate the topic or, at very least, think about. The discussions that follow are necessarily succinct. The first of these is the notion of identities in relation to the body and sport. Although the term identity has a long history (deriving from the Latin root idem implying sameness and continuity) it was not until the twentieth century that the term came into popular usage. The usage of the term in relation to body, sport and society has taken many forms, all of which have attempted to reinforce and challenge essentialist understandings of sport, body and society. Essentialism refers to the core identity (or identities) that remains after everything else has been peeled away and the extent to which sport and body cultures reproduce and reinforce essential identities. The historical contribution has highlighted the invented or constructed character of identity associated with many sporting traditions and body styles. As with other approaches, the historical approach views identity as essentialist but also contingent in that the identities are associated with body change over time and are therefore contingent upon particular histories. The psychodynamic approach to identity, 
body and sport has attempted to answer the question Who am I? and To what extent are the sporting and bodily practices I am involved in a reflection of self in a psychodynamic sense? The sociological approach to identity also has links to a theory of self in that a sociological tradition of identity theory has been linked to the symbolic interactionism associated with George Herbert Mead, Erving Goffman and Peter Berger. In this sense body identities have been explained through the process of socialisation, communication and body language all of which have attempted to reconcile the inner subjective creative bodily 'I' with the more outer, partly determined and objective 'Me'. With particular reference to sport, discussions of national identity have drawn upon the notion of sport helping to construct an imagined community while developmental or process sociologists have asserted that sport and the body are but vehicles for an overall quest for identity.

The notion of identity crisis has been evoked on a number of occasions to imply that identity only really becomes an issue when a particular, culture, social group, or nation is facing a crisis of identity. The notion of the body or sport reflecting an identity crisis is problematic in that it reduces discussions of body identity to being simply reactionary rather than body or sporting identities being enabling. More importantly, framing debates about the body and or sport in this way is not sensitive to particular identity crises unique to sport or body culture at any particular point in time. Did the impact of football hooliganism in the 1980s, 1990s, and beyond pose a particular crisis of identity for English football, or was English football simply reacting to broader social and cultural forces? On the other hand, if sport is viewed as a key component for the expression of national identity, then the fragmentation of different parts of the world may pose a particular crisis of identity for particular body cultures at local, national and international levels. Although chapter fourteen will argue that identity politics on its own is relatively meaningless, the notion of identity in crisis can contribute to an understanding of sport and body cultures in different parts of the world experiencing large-scale political upheaval or in places where new social forces attempt to dilute, replace or marginalise national identities. For example, to what extent have body cultures helped to reassert a new European identity that threatens national identities, or to what extent has sport reflected or enabled forms of reconciliation or a hardened militancy amongst various ethnic identities who were part of the former Yugoslavia? Thus, identities that are forged through sport, body and society may matter more if there is a real or perceived crisis of identity, globally, locally, personally and politically.

The second crucial concept is the notion of difference in relation to the body and sport. The marking of difference is crucial to the construction of identities in sport, body and society. In looking at how identities are constructed they tend to be formed in relation to other identities and thus essential differences are used to signify or represent identities. At its simplest this unsatisfactory trend tends to take the form of binary forms of classification such as us and them; insider and outsider; women and men; black and white; Arab and Jew; Protestant and Catholic; Serb and Croat. All of the aforementioned depend upon differences marking particular forms of identity that in turn symbolise or represent forms of social exclusion and political difference. The notion of difference is integral to the understanding, construction and in some cases invention of identities, all of which tend to be used to legitimate a particular social order or ways of being. More positively the recognition/acceptance of change and differences involving the body and sport may be seen as positively progressive in that it signifies the acceptance of a rich, diverse perhaps previously excluded set of body cultures such as gay and lesbian sporting culture; a sporting Olympiad rather than the able and disabled Olympics; and a secure place for Muslim Pakistani women in sociological accounts of sport and body cultures rather than a predominance of white/other feminist accounts of sport and the body. In this sense differences in and between sport and body cultures and identities may be viewed as a celebration of bodily diversity, heterogeneity and hybridity. Yet the notion of identity is not the same as difference in that one helps in the construction and legitimation of the other.

The final notion requiring comment is the notion of representations in relation to the body and sport. Representation refers to the ways in which images and texts such as articles, books, radio or television programmes reconstruct an account of sport, body and society. Thus a painting, a 
photograph, a written text about sport and the body are never just an actual sport or physical activity but how the painting, the photograph or the written text has represented sport and the body. Writers about gender and the body argue that representation is continually creating, challenging, re-creating and endorsing stereotypical images, stories, and ideas about identity, sport and the body. The areas of historiography and representation are crucial to developing post-colonial accounts of the sporting body. The work of Bale (2000) and other geographers of sport and Dimeo (2002) and other historians of sport offer alternative epistemological systems or ways of thinking about the sporting body that dislocate Eurocentric or colonial sporting histories and geographies.

Representing accounts of sport identities and the body can never be a neutral activity. Critical representations of sport and the body attempt to wrestle with and provide answers to questions of Who am I? What could I be? Who am I like and who do I want to be? Writers such as Bale and Dimeo could do a lot worse than take their lead from Edward Said who argued in Culture and Imperialism (1993, p. 230) that studying the relationship between the West and its dominated cultural other is not just a way of understanding an unequal relationship between unequal stories but also a point of entry into studying the formation and meaning of Western cultural practices themselves. Thus Said implied that the discrepancy of power between Western and non-Western sport necessitates that any account of global, international or local sport must take such a disparity into account if we are to accurately understand sport, body and society in its totality and not simply an illusion of totality. It is worthwhile to explore the issue of other sporting bodies in more detail if for no other reason than they have made a profound contribution to the story of sport, body and society. The politics of representation are such that all accounts of sport and the body that are promoted as authentic, valid and true need to closely questioned in order to ascertain just exactly where the authority and coherence for such claims maybe located.

\section{From identity politics to recognition through sport}

It is suggested here that those exploring identity politics in sport need to avoid decoupling the politics of identity in sport from social issues relating to the redistribution of wealth and power in sport. Identity in sport should not be viewed as an end in itself. By the same token, it is not being suggested that recognition in sport can be remedied by the redistribution of resources. Properly conceived struggles for recognition in sport can assist in the redistribution of power and wealth and should be aimed not at a promotion of essential fundamentalism but interaction and co-operation across gulfs of difference in sport.

There is no neat theoretical model that can be used to cleanly resolve the dilemma of identity and recognition in sport. However, the dilemma can be softened in various ways by acknowledging in part that the status model at least continues to recognize that social justice and a redistribution of wealth provides a social framework for thinking about sport, culture and society The status model recognizes that not all distributive injustices in sport can be overcome by recognition alone but it at least leaves the door open for a politics of redistribution. Unlike the identity model in sport, the status model continues to strive to understand recognition in sport alongside distribution. The status model of identity politics in sport works against tendencies to displace struggles for redistribution. It recognizes that status subordination is often linked to distributive injustice and therefore any notions of identity in sport would be closely aligned with notions of injustice and social change in sport. The model also avoids the problem of reification of group identities because the status of individuals and sub-groups within groups is part of the total pattern of recognition and social interaction. Thus identity in sport can invoke notions of social and political solidarity without masking forms of authority and power within such a collective form of identity.

It is not unrealistic to see such issues being played out in the world of sport. Following the collapse of apartheid in South Africa in 1992, the chief executive of the newly formed Department of Sport and Recreation in South Africa argued in 1997 that sport and recreation in the new South Africa 
had to meet the needs of the people and the nation. Identity through sport in the new South Africa was not enough but rather one of the questions facing the Department of Sport and Recreation and the government of South Africa was the manner in which the black athlete in South Africa would be compensated after decades of injustice as a result of apartheid polices. Speaking in Edinburgh in 1997 the chief executive said "From that premise of recognition of past injustices, we should be able to move forward to say: how then can we address and redress this legacy of denial and deprivation in sport for the majority of athletes in South Africa?" (Department of Sport and Recreation 1997, p. 4). At the same time it was suggested that sport in South Africa should not be the sole concern of the South African Department of Sport and Recreation but also the Supreme Council for Sport in Africa, the South Africa Truth and Reconciliation Commission. In this way sport in South Africa may be able to contribute to the renaissance of sport in Africa. It was this notion of sport in Africa that was behind Cape Town's bid to host the 2004 Olympic Games and the 2010 World Football Cup. Thus as argued above such an example can be viewed as being illustrative of the fact that identity in sport can invoke notions of social and political solidarity without masking forms of authority and power within such a collective form of identity. Clearly the initial phase of policy development in post-apartheid sport in South Africa practically illustrates that recognition in sport in the new South Africa was a collective effort but also that the international community should compensate South Africa for past injustices in some way shape or form.

Today's struggles for recognition in sport often assume the disguise of identity politics in sport. These are usually aimed at countering demeaning cultural representations of social, cultural, national, or local groups in sport. The result of mis-recognition in sport is that the struggle for identity by emphasising differences has enforced forms of separatism, conformism and intolerance but, more importantly, has displaced struggles for economic justice with the formation of reified identities. What is required is not the rejection of the politics of recognition in sport but rather an alternative politics of recognition that can remedy mis-recognition without fostering displacement and separatism or reification. The forgotten notion of status can provide a possible basis for examining recognition and struggles for redistribution in sport and with the help of sport. The status model of sport tends to reject the view that mis-recognition is free standing and it accepts that status subordination is often linked to distributive justice. Identity in sport cannot be understood in isolation nor can recognition be abstracted from distribution.

Cultural recognition then should not displace socio-economic redistribution as the remedy for injustice in sport even in a post-socialist age (Mair 2006, Therborn 2007). It is possible to think of one world of sport with many worlds in that world of sport. The goal for sport should not be identity as the end game but a framework that is not scared of close-up local democracy in sport and on the ground. Even the academic left in sport, the traditional guardians of social inequality in sport have lost interest in the commonalities that underpin differences and identities as if the logic of global sport has arrived in every corner of the globe. It has but to talk of identity in sport as if nothing else matters is to accept a zero-sum game that only serves to recognise and consolidate separatism and injustice in global sport.

\section{From recognition to redistribution and social justice}

It is perhaps necessary to leave sport for just a moment to emphasise the understanding and link between recognition, redistribution and social justice as basis for thinking about aspects of sport in society. Three different understandings of recognition maybe briefly mentioned. The first of these is a holistic conception of culture in which recognition means a commitment to redistributive ambitions often subsumed beneath weak forms of social democracy and social liberalism. The consequence for sport would be the need to embrace cultural diversity and identity as an authentic liberal moral imperative. The second understanding regards recognition as an on-going process and one that is integral to developing relations of political inclusiveness and a more democratic polity. The implications for sport being that recognition and the democratization of sport does not imply and end 
game but are in fact part of process that may contribute to a more or lesser degree of recognition which may have the unpredictable affect of benefiting or harming rival groups in unforeseen ways. A final notion of recognition, and the one advocated for in this chapter, is to view recognition as but one important dimension in the broader struggle for justice. It is not charity but justice that is the hallmark of any resource that is redistributive. Thus recognition is closely tied to a relationship with recognition and justice.

Current normative understandings of what constitutes the politics of identity tend to signify and have their roots in earlier periods or debates. The national tradition in sports research is at times all too pervading and needs to be balanced by a more trans-national or international approach about the importance of social identity, the belonging of indidviduals, freedoms and rights in and through sport. Today the relation between identity, recognition and redistribution cries out for examination. The struggles over gender, religion, nationality embedded in sport makes the question over recognition impossible to ignore. Crosscutting references to difference and representation are so intensely political that the question is likely to remain with sport for sometime. At the same time the need for redistributive justice and sporting injustice has not disappeared. Economic inequalities in sport continue to grow; neo-liberal forces promoting corporate globalisation continue to brush aside the question of distributive justice in sport.

It is precisely this notion of the relationship between recognition, redistribution and justice that needs to be placed at the heart of the normative debate about social identity. That is to say the emphasis to date. This is certainly true of much of the sports research in this area, which has placed too much of emphasis on the notion of identity and not enough on the social. Therefore the idea that research and education on identity and sport that reifies sporting identity does relatively nothing to determine or redress the cultural harm that is caused by reified models of identity in sport. It is crucial that such representations that are promulgated as authentic or true accounts of identity in sport are questioned, that their authority and coherence be closely examined and alternative, and that more socially orientated models of intervention be provided.

\section{The challenge to global sport}

The real challenge to global notions of sport in the twenty-first century is to take on board issues of recognition, redistribution and calls for social justice in sport. If nothing else, global sport needs to be framed in terms of democracy, accountability, transparency, trust and justice. At first glance the notion of global sport would seem to provide possibilities and opportunities for regulating sporting governance and finance to ensure a more equitable redistribution of sporting wealth. Any clear template for how sport in the world should be governed has not accompanied the transition towards a more global notion of sport. The governance of global sport is multi-layered, complex, national, local and international, but in all of these, states, sporting agencies, the sports market, civil societies and governing bodies of sport have all suffered from shortfalls with respect to popular participation and access, consultation and debate, inclusion and representation, transparency and accountability. Forms of global sporting governance through market-driven channels would seem to imply deep inequalities with the rule of efficiency overriding democracy. Supra-state sport organisations would appear to suffer from severe democratic deficiencies. At the moment it is unclear whether and how democracy can be adequately realized in a more global sporting world. Above all, Western sport embedded within national and increasingly European sporting governance, as well as the continuing dominance of American sporting capital, seems incapable of showing the historical imagination needed to grasp the radical challenges facing world sport. If global sport means recognising common situations, sharing a single world of sport, then the gaps between West and non-West, rich and poor, democratic and democratising will need a different kind of consciousness.

Global sport cannot make a significant difference in globalisation, but it can make a contribution. The enduring deep challenge for forms of global sporting democracy might involve some 
or all of the following ideas: (i) global sport must advocate a distinctive social agenda for sport; (ii) social democracy must become a distinctive feature of global sporting reform; (iii) global sporting organizations need to recognise that they have limited but significant powers to redistribute resource and wealth where it is most needed; (iv) global sport should institutionalise a framework for mobility and migration and monitor child labour and the production of sporting merchandise; and (v) recognise that the national identity model of sport can be dangerous if it leads to forms of reification.

Perhaps the emergence of a more socially committed approach to sport has to start from actively acknowledging the huge differences of opportunities, wealth, democracy, sporting tastes, and models of professional sport that divide the world. The deep challenge facing sport is to outline the mechanisms by which sport can be actively seen to contribute to social and economic welfare on an international scale. More powerful sporting nations would seem, at the international level, to have the power to enforce many of the rules and decisions affecting world sport and yet there are perhaps unprecedented opportunities in the twenty-first century in that sport is free from the Cold War politics of the twentieth century. Perhaps the most obvious and disturbing concern is the extent to which the core institutions of sport are trusted and sensitive to ways of addressing the interests of the majority in the non-Western world. The chief causes of inequality in sport remain twofold: the transformation of global sport by financial capital and the displacement of democratic political power in sport by unaccountable market power. As has been argued throughout this chapter it is not as if identity or recognition through sport is enough, but that if the point of recognition is going to be a meaningful power for social good in the world of sport, then those interested in covering the politics of identity in sport need to acknowledge that a redistribution of wealth is an important if not crucial aspect of any quest for recognition at any level. This is the challenge for not just sport but those public intellectuals who also see sport as a power for social good.

\section{REFERENCES}

Balakrishnan, G. (2002). The Age of Identity. New Left Review, 16, 130-142.

Bale, J. (2000). The Rhetoric of Running: the Representation of Kenyan Body Culture in the Early Twentieth Century. In L. Hansen, N. Nielsen (Eds.), Sports, Body and Health (pp. 123-133). Odense: Odense University Press.

Dimeo, P. (2002). Colonial bodies, colonial sport: 'martial' Punjabis, 'effeminate' Bengalis and the development of Indian football. International Journal of the History of Sport, 19, 72-90.

Fraser, N. (2003). Social Justice in the Age of Identity Politics. In N. Fraser, A. Honneth (Eds.), Redistribution or Recognition? (pp. 45-61). London: Verso.

Fraser, N. (2000). Re-thinking Recognition? New Left Review, 3, 107-120.

Frazer, E. (2000). Communitarianism. In G. Browning, A. Halcli, F. Webster (Eds.), Understanding Contemporary Society (pp. 46-58). London: Sage.

Fraser, N. (1995). From Redistribution to Recognition? Dilemmas of Justice in a Post-Socialist Age. New Left Review, 212, 1-24.

Fraser, N, Honneth, A. (2003). Redistribution or Recognition? London: Verso.

Hargreaves, J. (2000). Heroines of Sport: The Politics of Difference and Identity. London: Routledge.

Jarvie, G. (1997). Sport and Social Problems in Unprincipled Societies. In P. Nardis, A. Mussino, N. Porro (Eds.), Sport, Social Problems, Social Movement (pp. 16-28). Milan: Edizioni Seam.

Kenny, M. (2004). The Politics of Identity. Cambridge: Polity Press.

Klein, N. (2001). Reclaiming the Commons. New Left Review, 19, 81-90.

Mair, P. (2006). Ruling the Void and the Hollowing of Western Democracy. New Left Review, 43, 25-51.

Said, E. (2001). The Case for the Intellectual. The Age, May, 5-12.

Said, E. (1993). Culture and Imperialism. London: Chatto and Windus.

Therborn, G. (2007). After Dialetics - Radical Social Theory in a Post-Communist World. New Left Review, 43, 63-114.

Woodward, K. (2002). Identity and Difference. London: Sage Publications. 
AUTHOR'S ADDRESS: Grant Jarvie

University of Stirling

FK9 4LA Scotland, UK

Email: grant.jarvie@stir.ac.uk 